\title{
Analyzing IKEA's International Investment in China Based on the Theory of International Production Compromise
}

\author{
Pingxia Song, Rui Liu, Jun Li* \\ Foshan University, Foshan 528225, Guangdong Province, China \\ *Corresponding author: Jun Li, sp109814@sina.com
}

\begin{abstract}
This study analyzes IKEA's localized operation in China through the eclectic theory of international production. Firstly, the development history of IKEA is discussed along with its development in China. Secondly, IKEA's direct investment in China is analyzed from the perspective of IKEA's eclectic theory of direct investment in international production, the corporate ownership, internalization, and location advantages of the company, in addition to the challenges of IKEA's investment and operation in China, hoping to enlighten the process of formulating overseas expansion strategies for foreign direct investment. This study aims to guide students to strengthen their skills in formulating and implementing strategies in regard to the international investment process of multinational companies. On the one hand, they can analyze the strategies used and challenges faced by IKEA in its international investment in China to stimulate their thinking on the international investment of Chinese enterprises; on the other hand, they can also strengthen their understanding of the international investment theory by analyzing IKEA's international investment in China. This study hopes to enhance students' understanding and application skills in regard to companies' transnational operations.
\end{abstract}

Keywords: Ownership advantage; Internalization advantage; Differentiation strategy

Publication date: October 2021; Online publication: October 29, 2021

\section{Introduction}

IKEA was founded by Ingvar Kamprad in Sweden in 1943 with a history of 71 years. "Creating a better daily life for most people" is the direction IKEA has been working on since its establishment. Its brand has always been associated with improving people's quality of life and adhering to the business tenet of "providing as many customers as possible with affordable, well-designed, fully functional, and inexpensive household products."

Since the beginning of the 21 st century, China's real estate industry has sprung up, driving the vigorous development of China's furniture industry. As an international brand, IKEA has developed well in the European market. Due to the huge consumption potential in the Chinese market, IKEA chose to enter the Chinese market in 1998, breaking the rigid warehouse-style sales model of the domestic home furnishing market. The new concept has injected new vitality into the domestic home furnishing market and has been widely praised by domestic consumers. This article begins with IKEA's eclectic theory of direct investment in international production; then, it analyzes IKEA's direct investment in China as well as the challenges of IKEA's investment and operation in China from the advantages of corporate ownership, corporate internal management, and location, with a goal to direct foreign companies to the outside world. The investment in formulating overseas expansion strategies brings certain experience and enlightenment. 


\section{Overview of IKEA's development}

\subsection{Development history of IKEA}

As a well-known international home furnishing brand, IKEA has gone through three major stages in its development. The first stage is its initial brand establishment from 1943 to 1972. After the end of World War II, the world economy developed rapidly, and productivity greatly improved; the process of commercialization was fast-moving, and the demand for home furnishing brands in the market was increasing. Many home furnishing companies were developing rapidly during this stage. It is against this historical background that the IKEA home furnishing brand established its embryonic form of commercialization, and the overall favorable macro environment became an opportunity for IKEA's rapid development. The scale of IKEA's enterprise became larger, and its sales profit rose. The second stage was from 1973 to 1998, when the sales profits of its furniture stores in the local area accounted for about $80 \%$. After resource accumulation, IKEA began to set sights on the international market and eventually established 19 home furnishing sales markets and 26 home furnishing stores, with sales of up to 6.5 billion euros. This was the period of IKEA's assets expansion. The third stage is from 1999 to the present year. IKEA wanted to further expand its scale development but encountered the bottleneck of industrial chain management. Therefore, IKEA began to adjust its strategy and entered the international supply chain development mode. This allowed IKEA to obtain a profit of 38.8 billion euros in 2018 .

\subsection{Overview of IKEA's development in China}

Countries in the Asia-Pacific region are in a stage of rapid development, and there is great demand for all kinds of products. Due to the rapid development of China's economy and the escalation of residents' consumption capacity, China's furniture market has huge economic growth potential; thus, IKEA continues to increase its investment in China. IKEA opened its first furniture store in Shanghai in 1998 and set up its 33rd store in Guiyang, Guizhou by 2020, involving first-tier cities, such as Beijing and Shenzhen, as well as second-tier cities, such as Zhengzhou and Guiyang. As shown in Table 1, from the perspective of the number of stores, it can be seen that the expansion rate of IKEA in China is relatively slow, from 14 stores in 2013 to 27 stores in 2019. As the urbanization process in China accelerates, the consumption of household products is expanding, the income of Chinese consumers is increasing, and the personalization demand for household products is rising. IKEA's sales in China have grown steadily, and the Chinese market has become a new industry in the international household market. As a growth point, IKEA has increased its investment in China in all aspects.

Table 1. Number of IKEA stores and sales in China from 2013 to 2019

\begin{tabular}{ccccc}
\hline Year & Stores (houses) & Growth rate of stores $(\%)$ & Sales (100 million yuan) & Growth rate of sales $(\%)$ \\
\hline 2013 & 14 & 27.27 & 70 & 30.4 \\
2014 & 16 & 14.29 & 88 & 25 \\
2015 & 18 & 12.5 & 98 & 11.36 \\
2016 & 21 & 16.67 & 117 & 19.39 \\
2017 & 24 & 14.29 & 134 & 14.53 \\
2018 & 26 & 8.33 & 147 & 9.3 \\
2019 & 27 & 3.8 & 158 & 7.48 \\
\hline
\end{tabular}

Source: Based on IKEA's fiscal year 2019 report 
The development potential of the home furnishing market in China is valued by IKEA, and the procurement volume in China is increasing. IKEA has transferred logistics distribution from the Far East to Shanghai and set up regional distribution service centers in Shanghai, Malaysia, etc. The coordination of national distribution centers ensures the efficiency of IKEA's operations in the Asia-Pacific region in the international market. It also greatly accelerates the distribution of home furnishing products in IKEA stores, saves a lot of time and costs, and makes the entire supply chain more efficient. whole. IKEA has also established a huge central distribution center in Shanghai that uses differentiated distribution, covering many countries in the Asia-Pacific.

\section{Overview of the eclectic theory of international production}

The eclectic theory of international production is an economic theory of international enterprise production, proposed by a British economist, John Dunning. John Dunning gave a detailed and systematic explanation of the eclectic theory of international production in the book, International Production and Multinational Enterprises. He stated that the core concepts and viewpoints of the theory involve the decision of enterprises to directly invest abroad in international competition. The basic element depends on its own international ownership advantages, internalization advantages, and location advantages.

\subsection{Corporate ownership advantages}

Corporate advantage refers to a kind of ownership advantage which cannot be easily obtained by foreign enterprises that a country's enterprise already owns or can easily obtain. The advantage of international corporate ownership is a necessary prerequisite for international investment. If a company has ownership advantages, it may or may not choose international direct investment, but if the company does not have ownership advantages, it would certainly avoid international direct investment.

\subsection{Internalization advantages}

The advantages of enterprise internalization are mainly through the allocation of assets and internal management to effectively maintain and give play to the internalization advantages of the enterprise, so as to effectively avoid the impact of incomplete markets on the enterprise.

\subsection{Location advantages}

Location advantage refers to the advantages of the investment country or region for investors in terms of investment environment. It includes direct location advantages and indirect location advantages, which are the favorable factors of the host country and the unfavorable factors of the investment country, respectively.

\section{IKEA's investment analysis in China}

As an international brand, IKEA is making its way all over the world step by step. Due to the changes in the external environmental conditions of the domestic and foreign consumer markets as well as the enhancement of its own economic strength, the advantages and disadvantages of the international marketing route have gradually appeared in the market. In order to cope with the severe test of regional differentiation and effectively change IKEA's international route for the unfavorable or unfavorable factors highlighted, IKEA has formulated various marketing strategies and supporting measures, which are suitable for the local traditional culture based on the actual situation. This section analyzes the localization of IKEA in China based on the production compromise theory. 


\subsection{IKEA's ownership advantages}

\subsubsection{Brand advantage strategy}

The brand itself is an enterprise's "intangible asset" and a part of its core competitiveness. Building a good international brand image is not only used to guide the public imperceptibly, but also to attract consumers to certain products. In order to excel in the market, an enterprise must first create an excellent route for brand development. As the world's only well-known company specializing in international home furnishing products, IKEA's brand value, created by its international brand image, has always been in the forefront of the world.

\subsubsection{Capital advantage strategy}

The IKEA brand was valued at approximately 6.7 billion euros in 2005. During the ten years from 2011 to 2020, the total sales of IKEA have been continuously rising. In 2019, IKEA's retail sales reached 36.7 billion euros. In 2020, IKEA's annual sales reached 41.3 billion euros with a net profit of 2.9 billion euros. A sufficient financial support provides the economic foundation for IKEA's development in China.

\subsubsection{Low-cost strategy}

Through a series of reforms aimed at optimizing and controlling retail costs, IKEA has greatly reduced retail costs while ensuring the quality of its products and services. This allows IKEA to seize the market share with lower market prices than its competitors.

In order to reduce costs and market prices, IKEA's strategy is to first set the price and then determine the product. Generally speaking, manufacturers would first design the products and then price those products accordingly, but IKEA is different; it first determines a range of price, then designs the product, discusses the materials to be used, and finds suitable manufacturers for production. This method does not only allow IKEA to set optimized and reasonable prices, but also to produce products with the highest cost performance. Especially in an environment where small and medium-sized manufacturing industries are so intense in the Chinese market, IKEA has provided more opportunities for them by finding processing manufacturers for its production in China.

In order to maintain a low-cost strategy, IKEA has also adopted the flat panel concept for its products. Many IKEA products can be disassembled and reassembled. The flat packaging saves a lot of costs. It is not only beneficial for consumers in terms of convenient transportation of the products to their homes, but also for transportation containers as more products can be transported in view of the reduced volume; thus, optimizing the use of space. This type of transportation can carry several times the number of ordinary transports without split packaging. This can effectively reduce costs and maintain price advantages.

In addition, IKEA is also establishing more logistics distribution centers and warehouses in China. By cooperating with Chinese local processing manufacturers, increasing the purchase of semi-finished products, and reducing the purchase of raw materials, its costs can be reduced. Moreover, there are relatively few sales personnel in IKEA stores, which is in line with its low-price strategy.

\subsubsection{Differentiated marketing strategy}

In the face of market services, IKEA attaches great importance to customer feedback, adopts differentiated marketing strategies, and penetrates into each customer's family to discover the potential needs of customers.

(1) In terms of product design, IKEA has set up the only research and development (R\&D) center outside the Swedish headquarters in China - the Asia Pacific Product Development Center, inviting Chinese 
designers to design products that meet the preferences of Chinese consumers and check whether the products are in line with the preferences of the Chinese consumer market. In order to save costs, the design of products is not very different, but the accessories provided by manufacturers around the world are applicable to IKEA stores in various countries.

(2) In terms of retail mode, IKEA is very similar to Walmart, the king of retail. They both adopt largescale sales methods; they choose to locate at suburbs with convenient transportation and huge traffic as well as provide free parking services. In this manner, IKEA attracts the crowd with private cars. In addition, IKEA has also implemented a "value for money" strategy. In the launching stage of a new product with new functions and designs, a high-end route is chosen, which makes people feel that the new product is "value for money." When it goes on the market, the original price maintained by the new product will slowly fall to the "value for money" state, which would attract people who prefer to buy "value for money" products, satisfying both high-end and lower-end consumers. Increasing market share has also stimulated consumers' desire for continuous updating.

(3) In terms of marketing management, unlike traditional furniture display and sales, IKEA allows people to experience the joy of self-service marketing. This depends on IKEA's efforts to create a relaxed and casual experience for consumers while shopping. This is mainly reflected in "user active experience" and "transparent marketing." "Transparent marketing" clearly points out the advantages, disadvantages, and characteristics of the products; "user active experience," which is different from the practice of domestic home furnishing retailers who fear that consumers will damage the samples, emphasizes on customers' active experience. Customers can choose to view any model exhibition hall. As soon as customers walk through the door, rulers, pencils, etc. are provided, so that customers can participate in the planning of their personal homes. Customers can enjoy a comfortable shopping experience, gain authentic feelings, and then make correct judgments that meet their needs. This is very beneficial to IKEA because the purchase decision made by customers after a real and active experience would greatly reduce the possibility of disputes between the two parties. In addition, when customers are able to experience, the popularity of shopping malls would heighten, and it would be easier to realize customers' consumption desires.

(4) In terms of shopping environment, IKEA attaches great importance to the creation of a humanized shopping environment. The shopping guides in IKEA do not usually follow the customers throughout their shopping process but wait for them to make their own choices first. They would then come forward to provide services when the customers require explanation. This effectively avoids the boredom of consumers. In addition, every IKEA store is equipped with complete supporting facilities, such as European-style restaurants, children's playgrounds, etc., so that customers can truly enjoy in the process of shopping.

(5) In terms of one-stop service, IKEA is different from the single sales model of traditional domestic furniture retailers. The products it provides embody the entire product line. It does not only meet people's daily needs, but also provide products that are beyond expectations. The IKEA store is specially designed. Consumers only need to walk from one end to the other in order to see all the products. The simple and generous layout design is very attractive to people. 


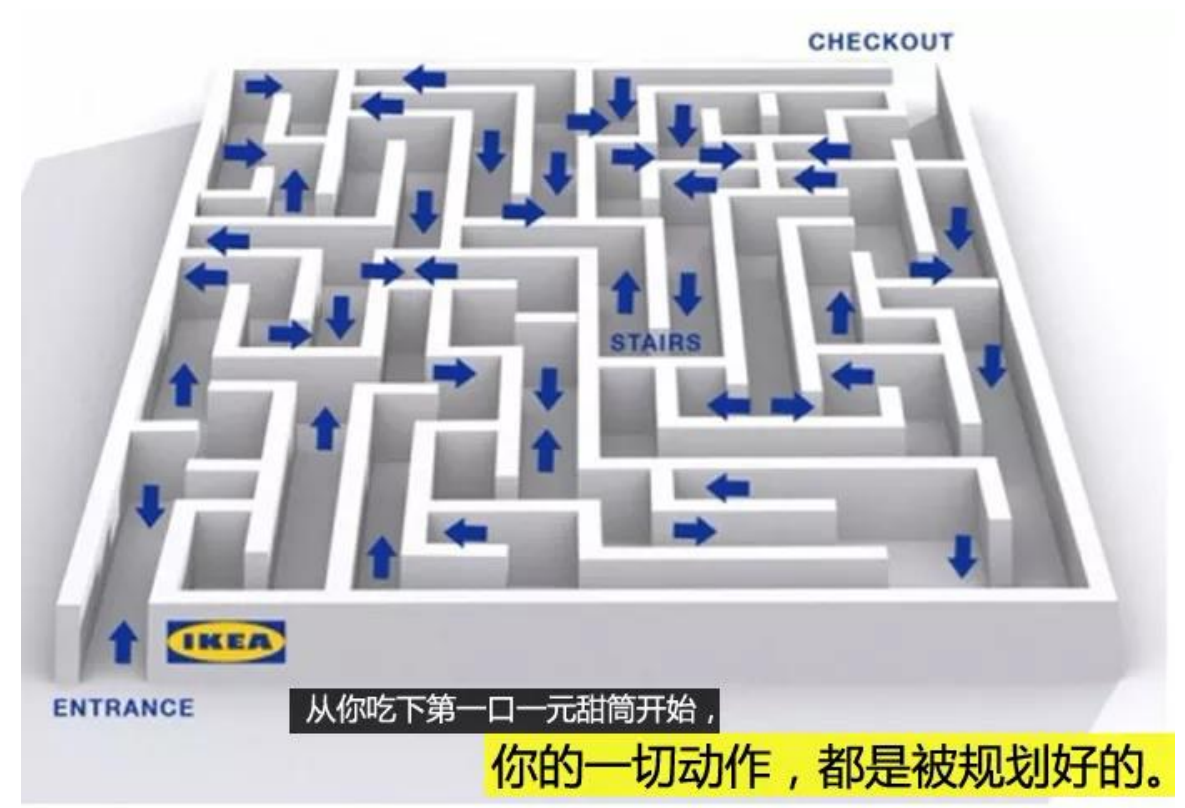

Figure 1. A model diagram of the IKEA store

(6) In terms of design and transportation, IKEA provides an opportunity for consumers to make clear requirements to the seller to customize the furniture they want, or they can creatively combine the different components of existing products according to their own preferences. Consumers do not have to passively accept the products that have been finalized. On the other hand, IKEA does not bear the transportation costs, but the consumers themselves have to do so. Favorable for consumers, the flat construction of IKEA's products is convenient for transportation; thus, consumers can package them as a whole and transport them to their homes for self-assembly. This is the difference between IKEA's "transportation link" in comparison to other furniture stores.

(7) In terms of organization, the design of consumer buying process is immutable for other companies. However, after locking the target consumer group, IKEA would analyze the consumer buying process in accordance with the specific needs of various groups. The systematic analysis is usually carried out in six stages, which include consumer buying process, distribution process, use process, follow-up replenishment process, maintenance process, and disposal process. Its ideology is to ensure that the customers understand the value the company wants to deliver. This is a blind spot in the current sales field in China, but it is a point of innovation in corporate marketing.

\subsection{IKEA's internalization advantages}

In order to avoid the adverse effects of external competition and market incompleteness on business operations, IKEA has successfully created and implemented a set of integrated market operations for product design, raw material procurement, processing, production, and sales in China. In addition, in order to reduce the pressure and uncertainty of external resource supply, IKEA has also set up a special sales service store in China to conduct face-to-face marketing with consumer suppliers in the United States as well as strictly control the supplier's sales access channels.

For IKEA, the Chinese market is the only international market with a complete supply chain besides the Swedish market. The integration of product design, experimentation, procurement, output, warehousing, transportation, sales, and other fields has expanded the marketing scope of the Chinese market. In November 2018, an online and offline simultaneous sales transformation was established in IKEA's first store in Beijing, which made its sales model in China transformed from a single to multichannel model. 


\subsection{China's location advantages}

\subsubsection{Strong support from policies}

The Chinese government has introduced many policies and measures to attract foreign investment and increase preferential treatment for foreign investment. For example, the State Council issued the Notice on Several Measures to Promote the Growth of Foreign Investment, calling for the active use of foreign investment an important measure of China's opening-up, further reducing restrictions on foreign investment access, as well as expanding the scope of market access and opening to the outside world. Large investments are very beneficial.

\subsubsection{Stable political environment}

In the past two decades, the Chinese government has not protected or subsidized the home furnishing industry. Therefore, the industry is in a freely competitive and fully market-oriented environment. Especially after China's accession to the World Trade Organization (WTO), the development of the Chinese furniture industry has been on a rise. Therefore, there are no barriers to the entry of IKEA's capital with barely any concern about entering China.

\subsubsection{Vast consumer market}

China's furniture market business is relatively fragmented, and there is no obvious monopoly, which provides an opportunity for IKEA to enter China. At the same time, China has a large population. The total population of first-tier cities in China has reached more than 10 million. This provides a good source of customers for IKEA. In terms of population structure, the rapid economic development of first-tier cities provides a better prospect for young people. Therefore, a large number of young people from various fields attempt to work and settle down in first-tier cities. Due to that, the age structure of first-tier cities is mostly at the youth level. When these young people plan to get married, the newly formed families are the main source of the furniture industry. Buyers provide IKEA with a lot of space for consumption. On the other hand, the home furnishing industry is a labor-intensive industry. A relatively cheap labor is required to set up IKEA in China, thus effectively reducing the costs.

Secondly, with the development of the economy and the improvement of residential housing conditions, children's home furnishings in China have become one of the consumption growth hotspots in the home furnishing market. Nowadays, the number of children in China is about 200 million. Children in many families have their own rooms. Children's furniture such as high-quality and inexpensive beds, writing desks, and bookcases are what most parents want to buy for their children. The sales volume of children's furniture has accounted for $18 \%$ of the total furniture sales. Therefore, children's furniture has a very broad market at this stage.

\subsubsection{Abundant human resources}

China has abundant human resources. China has fully implemented the China Education Modernization 2035 and the Implementation Plan for Accelerating Education Modernization (2018-2022) in order to accelerate the modernization of education. The number of talents receiving higher education continues to increase, and the advantages of professional talents are highlighted. IKEA demands its designers to combine product designs with the needs of target consumer groups, which has established a good reputation for IKEA products. In the Chinese market, IKEA recruits two types of talents: (1) undergraduates from excellent universities and focusing on postgraduate training as an absolute reserve of technical advantages; (2) those with rich working experience, such as sales talents and those with specialized skills 


\section{Challenges and opportunities faced by IKEA's operations in China}

\subsection{Challenges}

\subsubsection{Political environment}

Although China's entry into the WTO has stimulated the rapid development of the furniture industry, China's planning is relatively backward compared to developed countries, and its market access is relatively disorganized, which have caused vicious competition in the industry and the existence of low integrity condition.

In addition, on January 1, 2018, the new Labor Contract Law of the People's Republic of China was promulgated. The government has strengthened the supervision of statutory holidays as well as overtime working hours and wages. This guarantees the interests of laborers but have brought cost challenges to labor-intensive types of industries, such as IKEA.

From a global perspective, more emphasis has been on environmental protection, and stricter standards have been set for production, such as prohibiting the use of chemicals and heavy metals. China has also implemented the Environmental Protection Law, which also puts forward stricter requirements on the quality of IKEA home furnishing products.

\subsubsection{Dilemma in procurement}

IKEA's rigorous and idealized purchasing management method has some contradictions with Chinese manufacturing. Some suppliers who have cooperated with IKEA said that if they provide IKEA with a continuous increase in the output of manufactured products, it would be difficult for them to find a partner with such a large production volume like IKEA; thus, it would be difficult for them to leave IKEA. In this way, suppliers who consider IKEA's global supply system would think more carefully about cooperating with IKEA. In addition, cooperating with large multinational companies such as IKEA basically requires the adoption of original equipment manufacturer (OEM). The characteristic of OEM is that the market, capital, and technology are all external; only production is included. Therefore, although OEM can help companies digest excess productivity and effectively save social resources, it is not conducive to the research and development of the enterprises' own technology. As IKEA's corporate culture requires strict implementation of the supplier's best procurement philosophy, IKEA's suppliers are faced with the pressure of high standards in all aspects of the factory, including quality and social environmental responsibility. The high standards of IKEA's production and products demand a higher cost for the suppliers' materials.

In addition, IKEA has also encountered problems with suppliers' timber source control in China. IKEA has strict standards for the source of production materials. All wood used by IKEA must come from forest belts that have been professionally approved by the official supervision bureau, such as the Forest Management Committee. However, only two forest belts in China have passed the Forest Management Committee certification, both in the northeast region. Furthermore, China is paying much more attention to environmental protection and has introduced many environmental protection policies. In recent years, China has strictly controlled the amount of deforestation. IKEA has a huge demand for wood; therefore, these two forest farms cannot meet its requirements. In that case, suppliers have to obtain raw materials from certified forest farms in neighboring countries, thus increasing their cost. In consideration of the lowprice strategy of IKEA and the cost to source for timber, the profits gained by IKEA's suppliers are relatively small. Therefore, it is often difficult to find suitable suppliers in China who can work with IKEA for a long time. 


\subsection{Opportunities}

\subsubsection{Rapid development of e-commerce}

Since the third industrial revolution, computer and internet technologies have developed rapidly. Computer and internet technologies have largely influenced human activities, such as food, clothing, housing, transportation, and business activities. In such a big environment, e-commerce has become popular all over the world. With the transformation and development of China's economy, China's e-commerce has maintained rapid growth and created new consumer demand. IKEA, which is known for its offline experience marketing, is under pressure when facing the e-commerce market. If IKEA can combine the offline experience it provides with e-commerce marketing, it would be able to expand its sales market and maintain a higher growth rate in sales, but more importantly, it would be able to keep up with the development trend and implement omni-channel marketing.

\subsubsection{Improvement of consumption level and consumption concept of Chinese consumers}

According to the statistics from the National Bureau of Statistics, the per capita disposable income of Chinese residents in 2020 is 32,189 yuan, a nominal increase of $4.7 \%$ over 2019, and the per capita consumption expenditure is 21,210 yuan, an increase of $6.8 \%$ year-on-year. The per capita disposable income and consumption expenditure have increased year by year. As the generations born in the $80 \mathrm{~s}$ and 90s have become the drive of Chinese consumption, the consumption concept has improved. This growing consumer market provides opportunities for IKEA to operate in China.

\section{Funding}

This study was supported by the 2020 Graduate Free Exploration Fund Project (Item Number: 2020ZYTS54).

\section{Disclosure statement}

The authors declare that there is no conflict of interest.

\section{References}

[1] Su K, Fan Y, He C, 2020, Analysis of China's International Investment Based on the Theory of International Production Compromises - Taking IKEA and Geely as Examples. Modern Marketing (Late Edition), (11): 22-23.

[2] Wang J, 2018, Analyzing the Core Elements of the Successful Design of IKEA Home Furnishing Products. Art Technology, 31(02): 123.

[3] Yuan S, 2020, IKEA Home Furnishing Brand's Localization Development Strategy Analysis in China. News Culture Construction, (05): 119-120.

[4] Zhang Y, 2014, Research on the Application of Experiential Marketing in the Home Furnishing Store Industry. Tianjin University.

[5] Tan J, Duan P, 2018, IKEA (China)'s Localization Strategy Choice-Analysis Based on the SWOT Model. Journal of Henan College of Finance and Taxation, 32(02): 26-30. 